\title{
Einbruchhemmende Massnahmen in Arztpraxen
}

\section{Bruno Metzger}

Chef Sicherheitsberatung, Kantonspolizei St. Gallen

Korrespondenz: Fw Bruno Metzger Kantonspolizei St. Gallen Sicherheitsberatung Klosterhof 12 CH-9001 St. Gallen
In den vergangenen Monaten musste die Polizei in der ganzen Schweiz vermehrt Einbruchdiebstähle in Arzt- und Zahnarztpraxen registrieren.

Am Morgen nach den dreisten Tatbeständen stellten die Betroffenen fest, dass nahezu alle medizinischen Geräte mehr oder weniger fachmännisch demontiert und abtransportiert worden waren. Die Polizei geht davon aus, dass sich die Täterschaft dazu längere Zeit in der Praxis aufhielt und für den Abtransport des Deliktgutes geeignete Fahrzeuge verwendet hat.

Für die betroffenen Praxen bedeutete dies oft einen Betriebsunterbruch von mehreren Tagen. Spezialgeräte haben unter Umständen Lieferfristen von einigen Monaten. Selbst wenn die Versicherung den Schaden übernimmt, sind die Umtriebe im Schadenfall unangenehm.

Einbruchhemmende Massnahmen erschweren der Täterschaft die Aussicht auf Erfolg. Da die Täterschaft professionell vorgeht, müssen die Massnahmen kompromisslos sein. Eine fachgerecht installierte Alarmanlage mit Aufschaltung auf eine private Alarmzentrale wird empfohlen. Die Polizeistellen in allen Kantonen und grösseren Städten bieten eine persönliche Beratung vor Ort an. Dabei können die Berater dank der direkten Einbettung in die Kriminalpolizei vom Wissen und von der Erfahrung unserer Kollegen der Spurensicherung und Ermittlung profitieren.

Die Beratungen erfolgen unabhängig und neutral. Die Polizei gibt keine Firmenempfehlungen $\mathrm{ab}$.

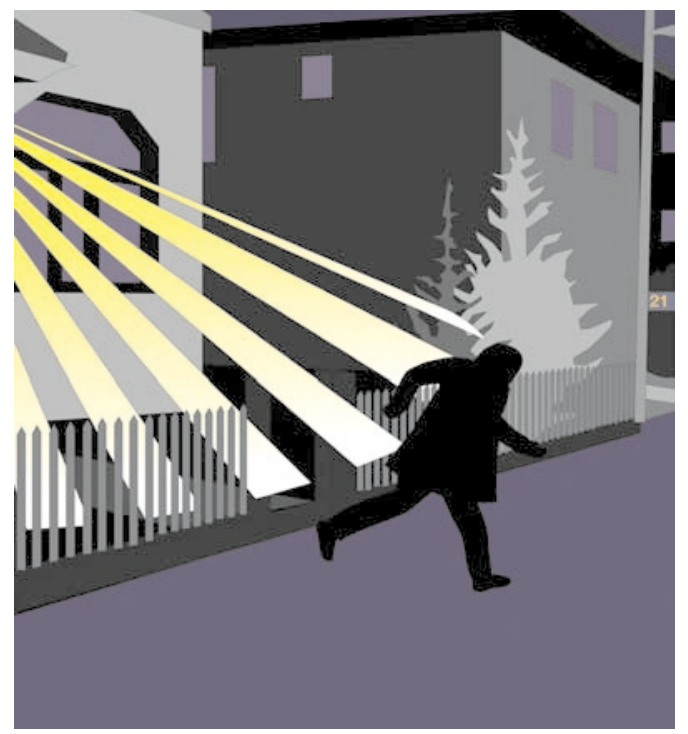

Abbildung aus der Broschüre «Einbruch - nicht bei mir!», die Sie unter www.kriminalpravention.ch einsehen können.

Im Telefonbuch oder auf der Homepage der Schweizerischen Kriminalprävention (www. kriminalpravention.ch) finden Sie die Adressen der Beratungsstellen.

Die Beratungen sind meist eine kostenlose Dienstleistung. Wenn Sie Interesse an einer Beratung haben, wenden Sie sich bitte an die Polizei, die am Standort Ihrer Praxis zuständig ist.

Die Polizei ist auf Ihre schnelle Meldung verdächtiger Feststellungen angewiesen 